\section{CONSENSUS PANEL OPINION FOR MINIMALLY INVASIVE AORTIC VALVE REPLACEMENT: ASSESSING POTENTIAL CONFLICT OF INTEREST}

\section{To the JTCVS Readers:}

In the January 2014 issue of The Journal of Thoracic and Cardiovascular Surgery, Malaisrie and associates ${ }^{1}$ published a consensus panel opinion document describing the intraoperative steps as well as key preoperative evaluation and planning and postoperative considerations for minimally invasive aortic valve replacement (MIAVR). Their recommendations were based on the combined experience of nearly 5000 MIAVRs performed by 20 surgeons at 19 institutions. Of the 20 surgeons, 19 reported consulting and/or lecture fees from Edwards; 6 from Medtronic; 4 from Atricure; 3 from St. Jude; and 1 each from Estech, Cardionet, Abiomed, Sorin, Mitralign, Abbott, LSI, Terumo, and Intuitive Surgical. The author list also included 2 fulltime employees of Edwards Lifesciences. All of these disclosures were clearly outlined on the first page of the manuscript, both in the printed journal and online. In addition, it is important to clarify that this manuscript went through an appropriate, thorough review by the Editor, Associate Editor, and independent reviewers who expressed no conflict of interest in regards to the content they evaluated.

\footnotetext{
The Editor welcomes submissions for possible publication in the Letters to the Editor section that consist of commentary on an article published in the Journal or other relevant issues. Authors should: - Include no more than 500 words of text, three authors, and five references. - Type with double-spacing. - See http://jtcs.ctsnetjournals.org/misc/ifora.shtml for detailed submission instructions. - Submit the letter electronically via jtcvs.editorialmanager.com. Letters commenting on an article published in the JTCVS will be considered if they are received within 6 weeks of the time the article was published. Authors of the article being commented on will be given an opportunity of offer a timely response ( 2 weeks) to the letter. Authors of letters will be notified that the letter has been received. Unpublished letters cannot be returned.
}

We found the text of this manuscript to be timely, very well-written, and beautifully illustrated. It should serve as an outstanding resource for surgeons interested in developing an MIAVR program. That being said, we feel it is important to clarify a potential conflict of interest that appears in this manuscript in regards to the specific equipment recommendations that exist in Appendix 1. Appendix 1 is a list of "author recommended products" organized into 14 distinct categories for MIAVR, and it is referenced throughout the manuscript. Nowhere, however, is there a clear description of how this product list was generated.

It is essential to point out that there are many alternatives available in the majority of these categories that are not included in the product list generated by the panel, and in many cases, the best option may not be included. In addition, some of the information presented is incomplete. One example occurs on page 9 of the text when the authors appropriately note that, "Smaller aortic cannulae are preferred (Appendix 1, 2)." Category 2 of the appendix then lists 2 aortic cannula options: The first (OptiSite from Edwards) is identified in size 18,20 , and $22 \mathrm{Fr}$, whereas the second (Sarns Soft-Flow from Terumo) is identified in size 21 and 24 Fr. The less experienced reader may then assume that the first choice is, therefore, best because it offers the smallest size. Unfortunately, the authors failed to mention that the Sarns Soft-Flow is also available in size $18 \mathrm{Fr}$; Terumo makes a high-flow aortic arch cannula down to size $12 \mathrm{Fr}$; and Medtronic, which was not included as an option, produces pediatric aortic cannulae down to size 6 Fr. These are the types of omissions that well-intending surgeons can make when trying to select products to recommend with which they may have a conflict of interest. Other omissions include the Carpentier Bi-Caval Femoral Venous Cannula from Medtronic, STAR soft tissue retractor from Estech, Chitwood DeBakey low-profile aortic clamp from Scanlon, and a myriad of chest drains to name but a few. It is also unclear how the order in which products were listed within a certain category was determined. It was not alphabetical by product; alphabetical by manufacturer; nor based on market share, panel vote, or a subjective measure of quality. In many categories, however, it does not appear random.

In summary, we feel that it is essential to reinforce to readers of the Journal that this appendix does not represent a complete list of available options to perform MIAVR nor does it necessarily include even the most appropriate option for each category. The authors are to be commended for including full disclosure of potential conflict of interest in the manuscript, but we all need to realize that it is virtually impossible for a person with a conflict of interest to recommend products in an unbiased fashion, no matter how hard they try.

Lawrence H. Cohn, $M D^{a}$ Marc R. Moon, $M D^{b}$

${ }^{a}$ Editor

The Journal of Thoracic and Cardiovascular Surgery

${ }^{b}$ Chair, Publications Committee

The American Association for

Thoracic Surgery Beverly, Mass

\section{Reference}

1. Malaisrie SC, Barnhart GR, Farivar RS, Mehall J, Hummel B, Rodriguez E, et al. Current era minimally invasive aortic valve replacement: techniques and practice. J Thorac Cardiovasc Surg. 2014;147: 6-14.

http://dx.doi.org/10.1016/ j.jtcvs.2014.01.016

\section{RARE TYPE OF \\ CARDIAC TUMOR IN A HEALTHY YOUNG WOMAN \\ To the Editor:}

Inflammatory myofibroblastic tumor is a relatively rare neoplasm of unknown etiology. It occurs at various 


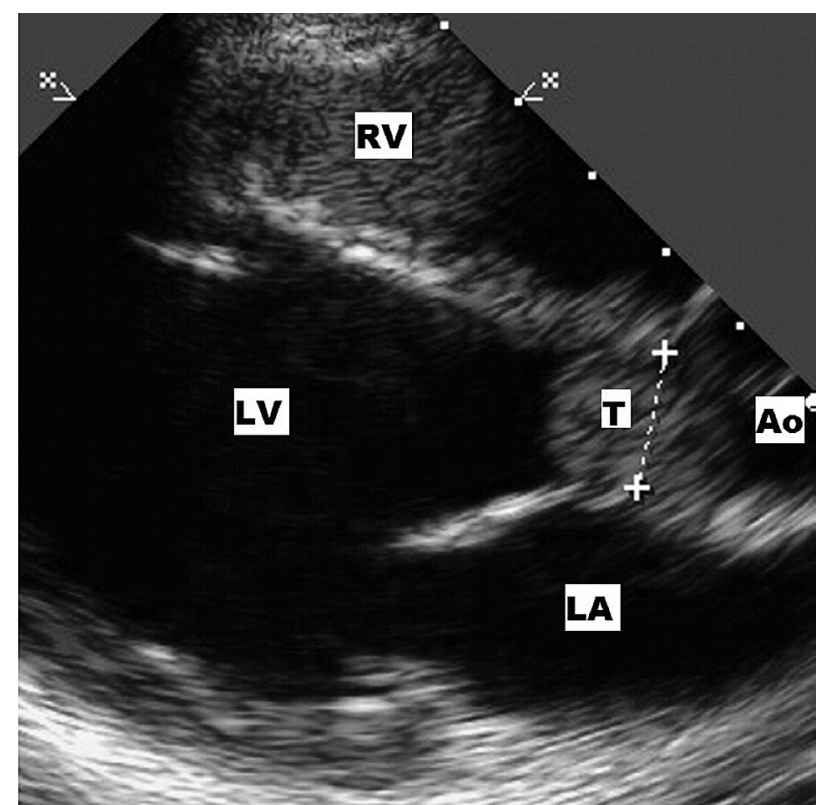

FIGURE 1. Preoperative echocardiography. $R V$, Right ventricle; $L V$, left ventricle; $T$, tumor (located in the left ventricular outflow tract); Ao, aorta; $L A$, left atrium.

sites but is usually located in the lungs. By definition, it is composed of spindle cells (myofibroblasts) with variable inflammatory components. Extrapulmonary forms are rare and are more common in adult female patients. ${ }^{1}$ The patients often are seen with fever of unknown origin and other vague, nonspecific symptoms. Inflammatory myofibroblastic tumor occurs extremely rarely in the heart. A study by Burke and colleagues ${ }^{2}$ demonstrated that the lesions may be located in the right atrium, right ventricular inflow tract, right ventricular outflow tract, mitral valve, aortic valve, left coronary sinus, or left ventricular free wall. Inflammatory myofibroblastic tumor is potentially dangerous. There have been cases described in which myocardial ischemia related to a tumor in the coronary artery resulted in sudden death. ${ }^{2,3}$

We report the case of a female patient, a student 21 years of age without relevant previous medical history, who was admitted to the

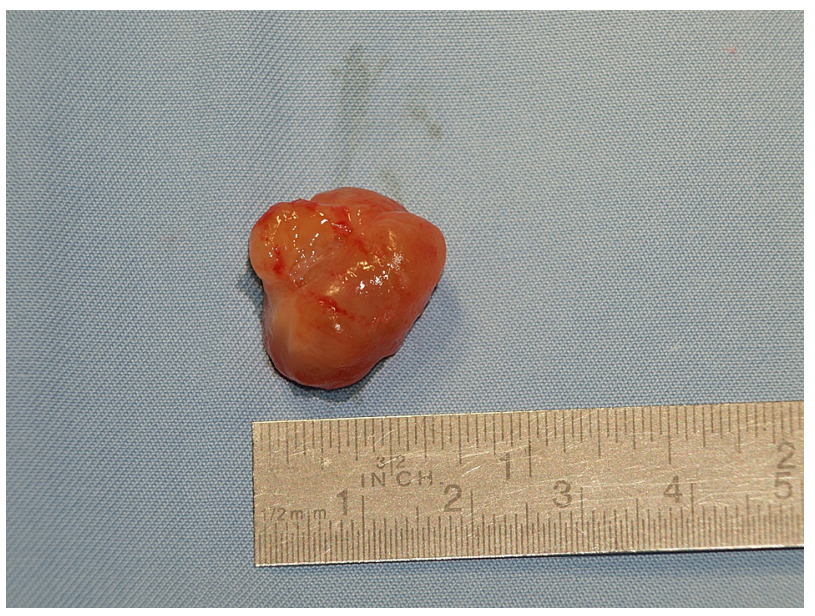

FIGURE 2. Gross appearance of resected tumor.

clinic after an incidental diagnosis of heart tumor. The patient had been seen with a 3-week history of symptoms of chest pain, fast heart beating, dizziness, and loss of consciousness. There were no significant changes in laboratory results, chest radiography, or electrocardiography. Under transthoracic echocardiographic examination, the tumor appeared as a mobile mass with a diameter of 1.5 to $2 \mathrm{~cm}$, causing a gradient of $39.3 \mathrm{~mm} \mathrm{Hg}$ in the left ventricular outflow tract (Figure 1). The aortic valve was found to be compliant, without any signs of insufficiency. Surgery was performed the day after the diagnosis was made, and the tumor was successfully resected (Figure 2). There were no complications in the postoperative period. Three years after the operation, the patient is free of symptoms, and there have been no new findings or tumor recurrence on echocardiographic examination.

\section{Krzysztof Jarmoszewicz, $M D, P h D^{a}$ Jan Rogowski, MD, $P h D^{a}$ Lidia Łepska, $M D, P h D^{b}$ \\ ${ }^{a}$ Department of Cardiovascular Surgery \\ University Clinical Centre Medical University of Gdansk Gdansk, Poland \\ ${ }^{b}$ Division of Noninvasive Cardiac Diagnostics Medical University of Gdansk Gdansk, Poland}

\section{References}

1. Attili SV, Chandra CR, Hemant DK, Bapsy PP, RamaRao C, Anupama G. Retroperitoneal inflammatory myofibroblastic tumor. World J Surg Oncol. 2005;3:66.

2. Burke A, Li L, Kling E, Kutys R, Virmani R, Miettinen M. Cardiac inflammatory myofibroblastic tumor: a "benign" neoplasm that may result in syncope, myocardial infarction, and sudden death. Am J Surg Pathol. 2007;31:1115-22.

3. Li L, Cerilli LA, Wick MR. Inflammatory pseudotumor (myofibroblastic tumor) of the heart. Ann Diagn Pathol. 2002;6:116-21. 